\title{
The Majority of Corona Mortis Are Small Calibre Venous Blood Vessels: A Cadaveric Study of North Indians
}

\author{
Sandeep Kashyap, MS, Yogesh Diwan, MD*, Shweta Mahajan, DNB ${ }^{+}$, \\ Deepa Diwan, MD*, Mukand Lal, MS, Randhir Chauhan, MS* \\ Departments of Orthopaedics, Anatomy*, and Anaesthesia and Intensive Care ${ }^{+}$, \\ Indira Gandhi Medical College, Shimla, India
}

Purpose: Corona mortis is an abnormal arterial or venous anastomosis between the external iliac and the obturator system of vessels and may cause significant hemorrhage during pelvi-acetabular fracture surgeries, hernia repair and laparoscopic gynecological procedures. Previous studies have estimated a prevalence of corona mortis between $34 \%$ and $70 \%$. This cadaveric study was conducted to estimate the prevalence of corona mortis in the North Indian population.

Materials and Methods: Twelve cadavers (24 hemipelvises; 11 males and 1 female) with a mean age of 68 (range, 54-82) years were included in this study.

Results: Corona mortis was observed in 14 hemipelvises (58.3\%). A total of 19 (79.2\%) vascular anastomoses of diameter greater than $1 \mathrm{~mm}$ were observed; 5 hemipelvises $(20.8 \%)$ had corona mortis on the right side, 9 hemipelvises $(37.5 \%)$ on the left side and bilateral in $5(41.7 \%)$ cases. Two hemipelvises $(8.3 \%)$ had an arterial connection. An aberrant obturator artery was observed in 1 (4.2\%) hemipelvis. A venous connection was found in 14 specimens (58.3\% of hemipelvises). The average distance of the connecting vein from the symphysis pubis was 41 (35-70) $\mathrm{mm}$. A vessel diameter of greater than $4 \mathrm{~mm}$ was observed in 4/24 (16.7\%) of hemipelvises.

Conclusion: The frequency of venous corona mortis was higher than arterial corona mortis and the majority (83.3\%) were small calibre $(<4 \mathrm{~mm})$. The presentation pattern and the number of arterial or venous anastomoses were different in the majority of hemipelvises and dissimilar in both hemipelvises of the same cadaver in the majority of cases.

Key Words: Anastomosis, Hemorrhage, Arterial, Venous, Acetabulum

Submitted: October 11, 2018 1st revision: November 12, 2018

Final acceptance: December 6, 2018

Address reprint request to

Sandeep Kashyap, MS

(https://orcid.org/0000-0002-6126-6844)

Department of Orthopaedics, Indira Gandhi Medical College,

Shimla, India

TEL: +91-177-2800187, +91-9418020187 FAX: +91-177-2800187

E-mail: drsk73arediffmail.com; drkashyapsandeepdagmail.com

This is an Open Access article distributed under the terms of the Creative Commons Attribution Non-Commercial License (http://creativecommons. org/licenses/by-nc/4.0) which permits unrestricted non-commercial use, distribution, and reproduction in any medium, provided the original work is properly cited.

\section{INTRODUCTION}

An anastomosis between the obturator and the external iliac or inferior epigastric vessels is known as the "corona mortis" (CMOR) or "crown of death". It is an anatomical variant located behind the superior pubic ramus at a variable distance from the symphysis pubis. Significant hemorrhage may occur if this structure is accidentally cut, and if occurring, is often difficult to achieve subsequent hemostasis ${ }^{1-5}$. This complication is a potential hazard for orthopedic surgeons, particularly during an anterior approach to the acetabulum; surgeons 
Sandeep Kashyap et al. The Majority of Corona Mortis Are Small Calibre Venous Blood Vessels

often resort to an alternative approach to avoid this catastrophic complication as deaths have been reported. CMOR is also a concern for general surgeons as it may cause complications during laparoscopic hernia repair ${ }^{6}$. Discrepancy between the reported prevalence of CMOR in cadaveric dissections and that found during surgery often exists. One often quoted theory is that these differences may be related to demographic and/or ethnic differences between study groups. Most previous studies have been conducted on western populations, with very few studies being published on Indian populations. The study was done to better elucidate the incidence of CMOR in North Indians; additionally, the available literature was reviewed for associated clinical implications.

\section{MATERIALS AND METHODS}

Twelve cadavers ( 24 hemipelvises) were used in this study. Of these cadavers, 11 were male and 1 was female with a mean age of 68 years (range, 54-82 years). The cadavers were donated for anatomical examination in accordance with the Himachal Pradesh Anatomy Act (1966). The study was performed in the Anatomy Department at the Indira Gandhi Medical College, Shimla after students had finished the dissection of anterior abdominal wall and the entire gastrointestinal system. Subsequently, the venous and arterial iliac systems were exposed and all branches were separated and identified. At the pubic bone, the peritoneum was released from the superior pubic ramus and the urinary bladder moved away from the pubic bone. The retropubic space occupied by a variable amount of fat was exposed carefully. At the superior pubic ramus, every vessel with a diameter of $\geq 1 \mathrm{~mm}$ was preserved. All vessels connecting the obturator vessels with the external iliac or inferior epigastric systems and aberrant vessels were identified and recorded. The obturator artery was identified on the inner wall of the pelvis and the possibility of its communication either with the accessory obturator artery, inferior epigastric artery or external iliac artery was considered. The diameter was measured by two authors (author 1 and 2) using vernier calliper just touching the external surface of the vein or artery (reading error, $0.02 \mathrm{~mm}$; resolution, $0.01 \mathrm{~mm}$ ) ${ }^{6}$ and the average of both readings was taken.

\section{RESULTS}

A total of 19 vascular anastomoses of diameter greater than $1 \mathrm{~mm}$ were observed between the obturator vessels and external iliac or inferior epigastric vessels in 14 (79.2\%) hemipelvises. CMOR was observed in 5 hemipelvises $(20.8 \%)$ on the right side, 9 hemipelvises $(37.5 \%)$ on left side and bilaterally in $5(41.7 \%)$ cases (Table 1). Three (25.0\%) cadavers had no anastomosis. Only 1 cadaver $(8.3 \%)$ had similar anastomoses in both hemipelvises, and the remaining eight had either dissimilar presentation or no communication in the opposite hemipelvis. In 2 hemipelvises $(8.3 \%)$, both arterial and venous anastomosis were observed; one case had one venous and one arterial vessel, and the other had one arterial and two venous vessels. In 4 specimens (16.7\%), a large diameter vessel (>4 mm) was present (Table 2) and in one venous communication, the diameter observed was $10 \mathrm{~mm}$. On average, CMOR were present $5.6 \mathrm{~cm}$ (range, $3.5-7.0 \mathrm{~cm}$ ) lateral to the pubic symphysis.

\section{Arterial Corona Mortis}

Of the 24 cadaveric hemipelvises, $2(8.3 \%)$ had an arterial anastomosis. The artery passed vertically in one case to the upper surface of the superior pubic ramus forming a "vascular arch" around the superior pubic ramus $5.7 \mathrm{~cm}$ from the pubic symphysis (Fig. 1) and connected the distal part of the obturator artery with the external iliac artery at the level of origin of inferior epigastric artery; two venous anastomoses were also present in this case. In another case, there was an abnormal obturator artery arising from the inferior epigastric artery, running over the superior pubic ramus, $4.5 \mathrm{~cm}$ from the pubic symphysis and branching to the urinary bladder before leaving the pelvis through the obturator foramen (Fig. 2); this case also had a venous communication.

\section{Venous Corona Mortis}

Venous anastomoses were more common than arterial. A venous connection was observed in 14 specimens (58.3\% of hemipelvises), and $78.6 \%$ of these cases involved a single venous anastomosis. The average distance of the connecting vein from the symphysis pubis was $41 \mathrm{~mm}(35-70 \mathrm{~mm})$. The anastomosing vein 
Hip Pelvis 31(1): 40-47, 2019

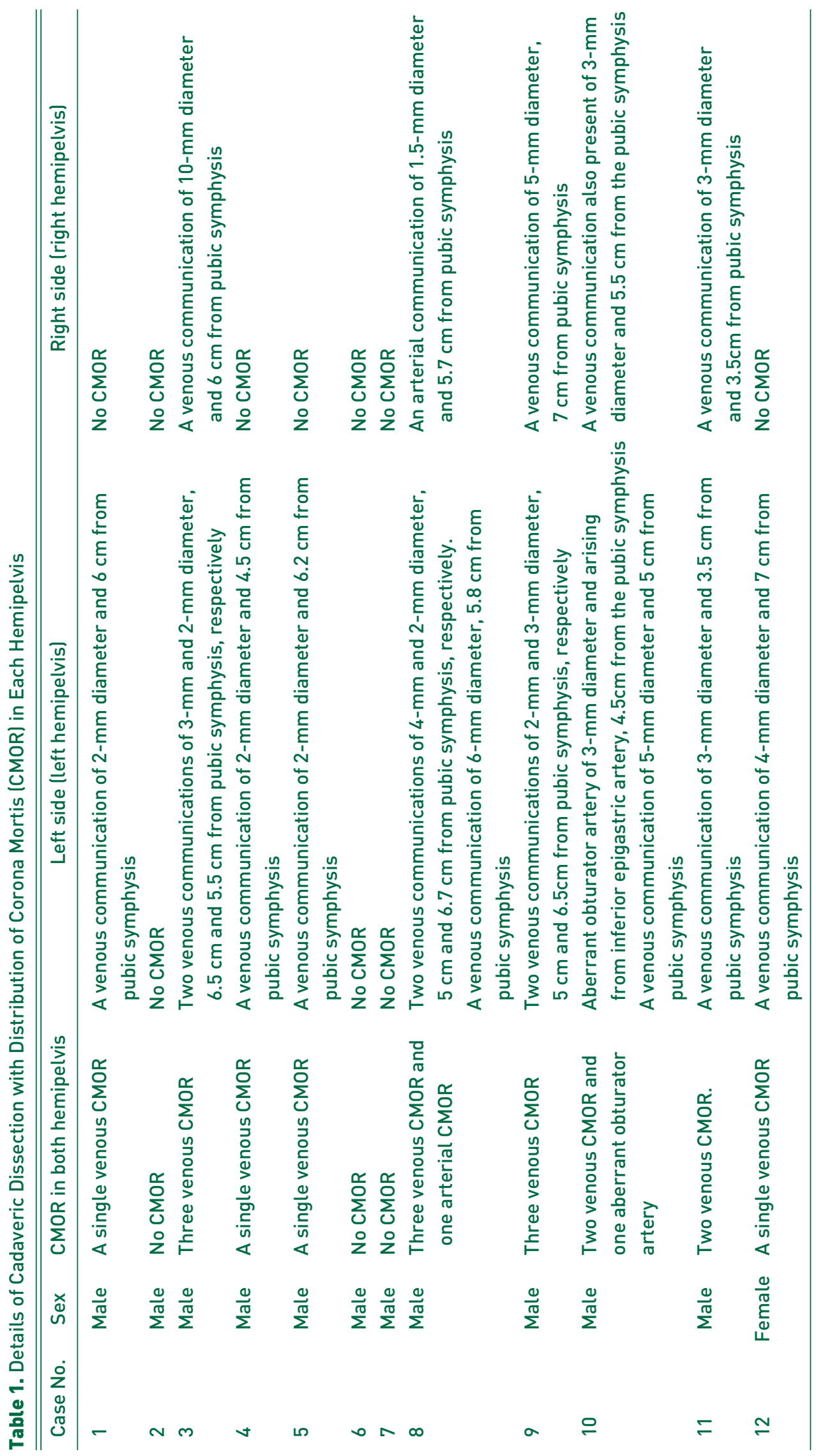




\section{Hip \& Pelvis}

Sandeep Kashyap et al. The Majority of Corona Mortis Are Small Calibre Venous Blood Vessels

passed over the superior pubic ramus behind the iliopectineal eminence and connected to the obturator vein (Fig. 3).

\section{DISCUSSION}

Abnormal anastomotic vessels between the external iliac and the obturator systems have been referred to as the CMOR and may involve an artery(ies), vein(s) or both $^{7,8)}$. The wide variation in the incidence of CMOR (i.e., 29-84\%) suggests ethnic or regional differences (Table 3$)^{3,9-15)}$. In our study, we observed CMOR in 58.3\% of cases-a percentage comparable to a study conducted by Nayak et al. ${ }^{15)}$ in South India. However, we were unable to identify any earlier study of a North Indian population.

Table 2. Vascular Distribution in the Dissection

\begin{tabular}{lc}
\hline \hline Vessel & Side (hemipelvises) \\
\hline Crossing the superior pubic ramus & $14 / 24(58.3)$ \\
Any vessel diameter $>4 \mathrm{~mm}$ & $4 / 24(16.7)$ \\
Arterial anastomosis & $2 / 24$ ( 8.3) \\
Venous anastomosis & $14 / 24(58.3)$ \\
Multiple venous anastomosis & $3 / 24(12.5)$ \\
Both vein and artery & $2 / 24(8.3)$ \\
Bilateral vascular abnormalities & $5 / 12(41.7)$ \\
Bilateral symmetry in vascular & $1 / 12(8.3)$ \\
distribution & \\
Aberrant obturator artery from & $1 / 24(4.2)$ \\
external iliac artery & \\
\hline
\end{tabular}

Values are presented as number $(\%)$.
Pellegrino et al. ${ }^{14)}$ in 2014 studied 25 patients laparoscopically and observed CMOR in $60 \%$ (15 hemipelvises) on the right side, $28 \%$ (7 hemipelvises) on left side and bilaterally in 3 out of 25 cases. In our study, CMOR was observed in 9 hemipelvises $(37.5 \%)$ on left side and bilaterally in 5 cases $(41.7 \%)$. In this study, a single venous communication was seen in $83 \%$ of cases with venous anastomosis-similar to findings by Pellegrino et al. ${ }^{14)}$ (i.e., 78.6\%). Nayak et al. ${ }^{15)}$ observed bilateral CMOR in only three out of 69 cases $(4.3 \%)$ studied. In our study bilateral presentation of CMOR was higher compared to previous studies.

\section{Arterial Corona Mortis}

Arterial anastomosing channels have been mentioned less frequently than venous connections and the prevalence of arterial CMOR has been reported to be between $8 \%$ and $62.5 \%$. In 1996 , Tornetta et al. ${ }^{9}$ dissected 50 cadaver halves and observed an arterial connection in only $34 \%$ of them. Teague et al. ${ }^{2)}$ (1996) reported that $43 \%$ of specimens had a single large diameter communicating artery. Okcu et al. ${ }^{12)}$ (2004) observed arterial anastomoses in $19 \%$ of their anastomosing vessels. Hong et al. ${ }^{3}$ (2004) observed that $34 \%$ of anastomotic vessels were arterial. Rusu et al. ${ }^{13}$ (2010) observed arterial anastomoses in $62.5 \%$ of cases. Pellegrino et al. ${ }^{14)}$ (2014) reported that arterial anastomoses were only $8 \%$ of their anastomosing vessels, while Ates et al. ${ }^{16)}$ (2016) observed it in $28.4 \%$ cases. More recently, Nayak et al. ${ }^{15)}$ (2016) dissected 73

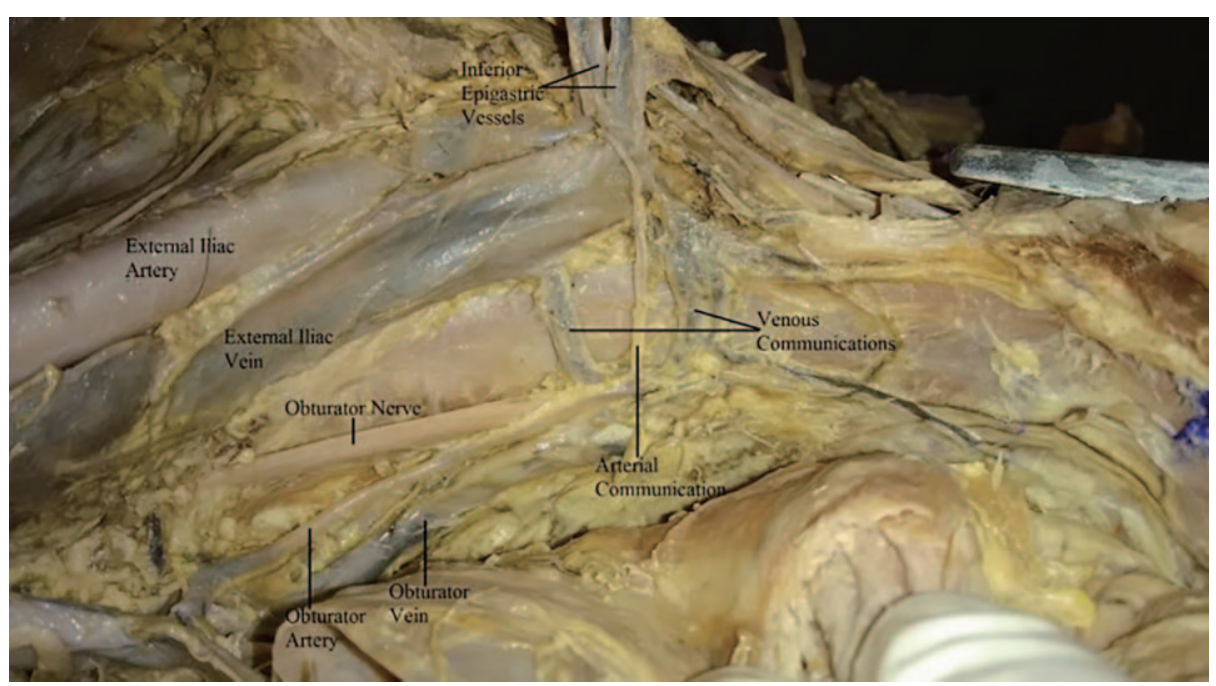

Fig. 1. One arterial communication between obturator artery and external iliac artery and two venous communications between obturator vein and external iliac vein. 


\section{Hip \& Pelvis}

Hip Pelvis 31(1): 40-47, 2019

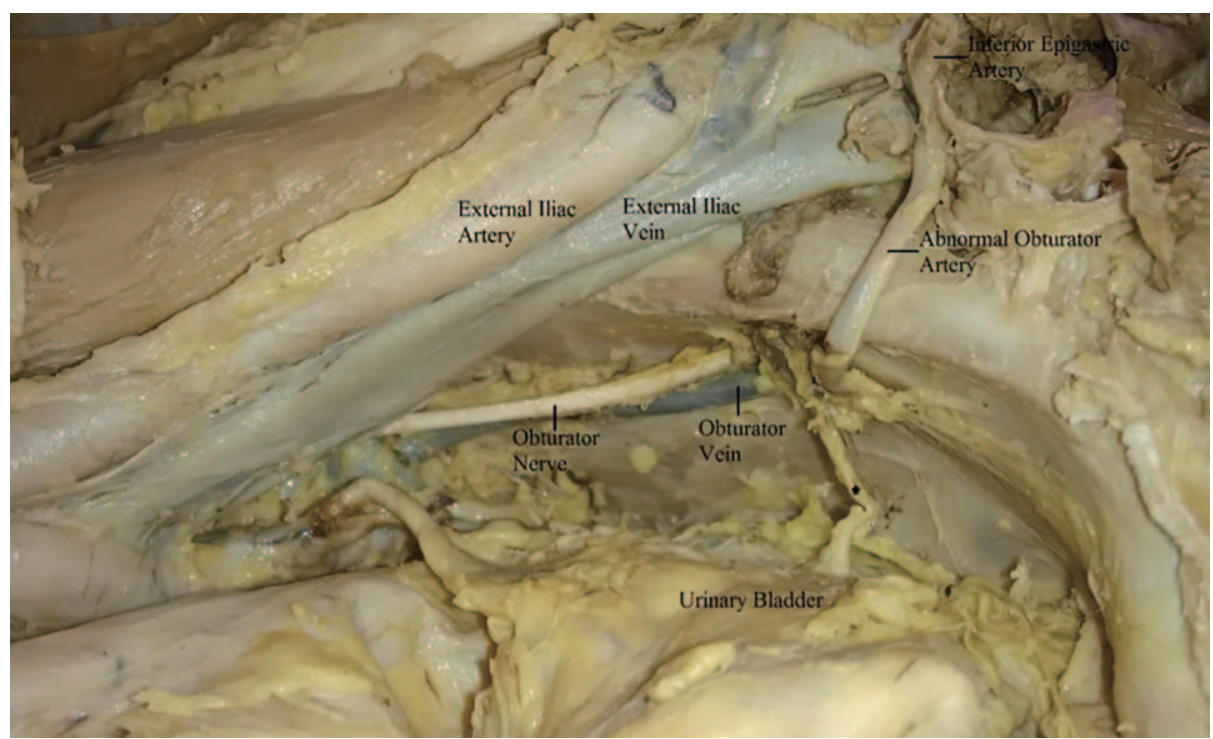

Fig. 2. An abnormal laberrant) obturator artery arising from the inferior epigastric artery. In this case the normal origin of obturator artery from Internal iliac artery was not seen.

* Branch to the urinary bladder from the abnormal obturator artery.

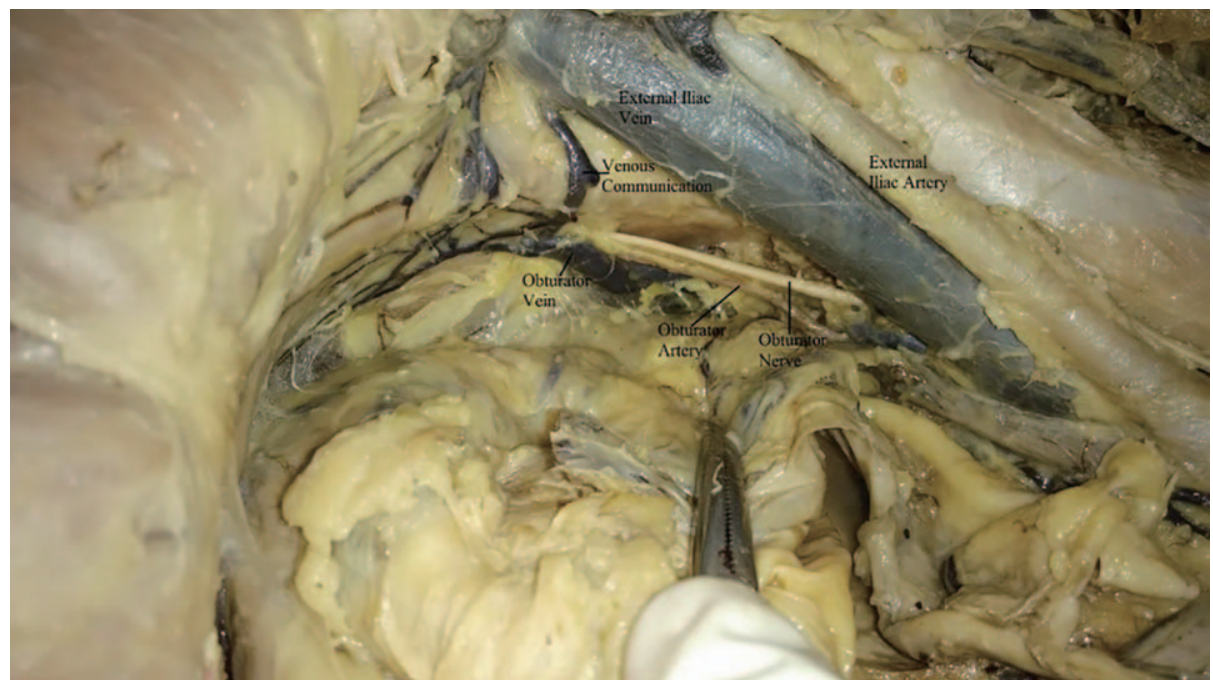

Fig. 3. A venous communication between obturator vein and external iliac vein.

Table 3. Incidence of Corona Mortis

\begin{tabular}{|c|c|}
\hline Study & Ratio of cases with corona mortis (\%) \\
\hline Tornetta et al.9) (1996) & 84.0 \\
\hline Hong et al. ${ }^{33}(2004)$ & 72.0 \\
\hline Pungpapong and Thum-umnauysuk ${ }^{101}$ (2005) & 77.2 \\
\hline Darmanis et al. ${ }^{111}$ (2007) & 83.0 \\
\hline Okcu et al..$^{21}(2004)$ & 61.0 \\
\hline Rusu et al. ${ }^{13)}(2010)$ & 40.0 \\
\hline Pellegrino et al. ${ }^{14)}$ (2014) & 52.0 \\
\hline Nayak et al. ${ }^{15)}(2016)$ & 51.0 \\
\hline Current study & 58.3 \\
\hline
\end{tabular}


Sandeep Kashyap et al. The Majority of Corona Mortis Are Small Calibre Venous Blood Vessels

hemipelvises and observed an arterial connection in $8.22 \%$. In our study, arterial CMOR was present in 2 cases $(8.3 \%)$-a percentage similar to previous studies by Pellegrino et al. ${ }^{14)}$ and Nayak et al. ${ }^{15)}$ (albeit on the lower side).

\section{Venous Corona Mortis}

In this study, the frequency of venous CMOR was found to be higher than arterial CMOR. Its incidence has been described to vary between $37.5 \%$ as observed by Rusu et al. ${ }^{13)}$ (2010) to $96 \%$ by Berberoğlu et al. ${ }^{5)}$ (2001), which they believed may endanger laparoscopic procedures. This venous connection was found to have no relation with the presence of arterial CMOR or vice versa. In 1996, Tornetta et al. ${ }^{9}$ reported that $70 \%$ of their specimens had a venous connection. According to Teague et al.. (1996), 59\% cases have venous channels connecting the obturator with either the inferior epigastric or external iliac vein. Okcu et al. ${ }^{12)}$ (2004) observed vascular communication between the obturator and external iliac systems in $61 \%$ of cases studied. A similar incidence (i.e., 62\%) was reported by Hong et al. ${ }^{3)}$ (2004). Kacra et al. ${ }^{17)}$ (2011) observed venous CMOR in $40 \%$ of cases, Pellegrino et al. ${ }^{14)}$ (2014) in $46 \%$ cases, and more recently, Nayak et al. ${ }^{15)}$ (2016) observed that in $68 \%$ cases there is a venous communication between the obturator and either the inferior epigastric or external iliac vein. These results were consistent with our observations.

Although the incidence of aberrant obturator artery has been found to be as high as $44 \%$ in a study by Missankov et al. ${ }^{18)}$, we observed it in only 1 hemipelvis (4.17\%)-a percentage similar (albeit on the lower side) compared to previous studies by Jakubowicz et al. ${ }^{19}$ and Berberoğlu et al. ${ }^{5)}$ (Table 4) ${ }^{5,18-21)}$. The symmetrical presentation of CMOR (venous/arterial) in both hemipelvises was observed in only $1 / 12(8.3 \%)$ cadavers in our study, an observation not mentioned in any previous studies. Similarly, both arterial and venous anastomoses in the same hemipelvis was seen in only 2 hemipelvises $(8.3 \%)$ which is higher compared to previous study by Nayak et al. ${ }^{15}$ which found this presentation in 3/69 (4.3\%) cases. In our study, most of the anastomoses seen were small caliber vessels; large caliber vessels were observed in only 4/24 (16.7\%) hemipelvises. To the best of our knowledge this has not been studied or reported previously.

The CMOR is also very important in gynecological operations and hernia repair, especially obturator hernia $^{22}$. CMOR can be damaged during fixation of the mesh on Cooper's ligament in laparoscopic hernioraphy that can cause uncontrollable bleeding, retroperitoneal hematoma, conversion to open surgery and reoperation. In clinical practice the incidence of excessive hemorrhage from an abnormal vessel around the superior pubic ramus is lower ${ }^{23)}$.

Interestingly, most CMOR observed during cadaveric dissections are small caliber vessels and insignificant. This discrepancy with the clinical cases may be related to the demographic and ethnic features among the different study populations ${ }^{24)}$ or due to the spasm of the lacerated CMOR vessel during displaced fractures thus making them difficult to identify at the time of operation $^{2,12,13,15,17)}$. Surgeons frequently using the ilioinguinal or Stoppa's approach rarely encounter CMOR as it is usually thrombosed by the fracture since most of the vessels are small caliber. However, during this surgical approach, large diameter and aberrant obturator arteries-although rare-may also be found. Importantly, controversy still exists regarding ligation of aberrant obturator artery if found during surgery as it can produce disastrous results. These can cause excessive intraoperative hemorrhage if inadvertently

Table 4. Incidence of Aberrant Obturator Artery

\begin{tabular}{lcr}
\hline \hline Author & Hemipelvises studied (n) & Aberrant obturator artery (\%) \\
\hline Jakubowicz et al. ${ }^{19)}(1996)$ & 75 & 6.6 \\
Missankov et al. ${ }^{18)}$ (1996) & 49 & 44.0 \\
Berberoğlu et al. ${ }^{.1}(2001)$ & 14 & 7.1 \\
Sarikcioglu et al. $(2003)$ & 54 & 14.8 \\
Maneesha et al. ${ }^{201}(2012)$ & 60 & 6.6 \\
Al Talalwah ${ }^{21)}(2016)$ & 208 & 9.8 \\
Current study & 24 & 4.1 \\
\hline
\end{tabular}


injured and deaths have been reported.

Darmanis et al. ${ }^{11)}$ observed a high incidence of CMOR in all cadaveric specimens; however, very few patients undergoing surgery of acetabulum were found to have CMOR. This group suggests caution be exercised during surgery, but advised against modifying/altering the surgical approach for fear of hemorrhage. Whether preoperative angiographic analysis in all patients undergoing surgery for fractures of acetabulum by ilioinguinal/Stoppa's approach can help the surgeons and make them wiser preoperatively needs to be studied. More computed tomography angiographic studies comparing the incidence of CMOR in fractures of the acetabulum or pelvis with normal side or normal populations may be of help in the future. Moreover, the reading error by Vernier calipers as described by Stavropoulou-Deli and Anagnostopoulou ${ }^{6}$ is $0.02 \mathrm{~mm}$ with a resolution of $0.01 \mathrm{~mm}$. However, the shape of the vein is collapsed in cadavers and the inter-measurer error range is expected to be larger than in living individuals. The limitation of our study is the small sample size; a larger sample size may shed additional light on this subject and contribute to our understanding and of CMOR in North Indians.

\section{CONCLUSION}

In summary, a small caliber venous communication between the obturator and the external iliac or inferior epigastric systems was located over the superior pubic ramus in a high percentage of cadaveric dissections compared with arterial anastomosis. There is no relation between the presence or absence of arterial or venous CMOR with respect to each other, they can be present unilaterally or bilaterally. Even when present bilaterally, the manifestation may be different. Its diameter and course varies and on average is present $5.6 \mathrm{~cm}(3.5-7.0$ $\mathrm{cm})$ lateral to the pubic symphysis.

\section{CONFLICT OF INTEREST}

The authors declare that there is no potential conflict of interest relevant to this article.

\section{REFERENCES}

1. Sarikcioglu L, Sindel M, Akyildiz F, Gur S. Anastomotic vessels in the retropubic region: corona mortis. Folia Morphol (Warsz). 2003;62:179-82.
2. Teague DC, Graney DO, Routt ML Jr. Retropubic vascular hazards of the ilioinguinal exposure: a cadaveric and clinical study. J Orthop Trauma. 1996;10:156-9.

3.Hong HX, Pan ZJ, Chen X, Huang ZJ. An anatomical study of corona mortis and its clinical significance. Chin J Traumatol. 2004;7:165-9.

4. Marsman JW, Schilstra SH, van Leeuwen H. Angiography and embolization of the corona mortis (aberrant obturator artery). A source of persistent pelvic bleeding. Rofo. 1984;141:708-10.

5. Berberoğlu M, Uz A, Ozmen MM, et al. Corona mortis: an anatomic study in seven cadavers and an endoscopic study in 28 patients. Surg Endosc. 2001;15:72-5.

6. Stavropoulou-Deli A, Anagnostopoulou S. Corona mortis: anatomical data and clinical considerations. Aust $N \mathrm{Z} \mathrm{J}$ Obstet Gynaecol. 2013;53:283-6.

7. Letournel E. The treatment of acetabular fractures through the ilioinguinal approach. Clin Orthop Relat Res. 1993; (292):62-76.

8. Letournel E, Judet R. Fractures of the acetabulum. 2nd ed. Berlin: Springer; 1993.

9. Tornetta P 3rd, Hochwald N, Levine R. Corona mortis. Incidence and location. Clin Orthop Relat Res. 1996; (329):97-101.

10. Pungpapong SU, Thum-umnauysuk S. Incidence of corona mortis: preperitoneal anatomy for laparoscopic hernia repair. J Med Assoc Thai. 2005;88:S51-S53.

11. Darmanis S, Lewis A, Mansoor A, Bircher M. Corona mortis: an anatomical study with clinical implications in approaches to the pelvis and acetabulum. Clin Anat. 2007;20:433-9.

12. Okcu G, Erkan S, Yercan HS, Ozic U. The incidence and location of corona mortis: a study on 75 cadavers. Acta Orthop Scand. 2004;75:53-5.

13. Rusu MC, Cergan R, Motoc AG, Folescu R, Pop E. Anatomical considerations on the corona mortis. Surg Radiol Anat. 2010;32:17-24.

14. Pellegrino A, Damiani GR, Marco S, Ciro S, Cofelice V, Rosati F. Corona mortis exposition during laparoscopic procedure for gynecological malignancies. Updates Surg. 2014;66:65-8.

15. Nayak SB, Deepthinath R, Prasad AM, Shetty SD, Aithal AP. A South Indian cadaveric study on obturator neurovascular bundle with a special emphasis on high prevalence of 'venous corona mortis'. Injury. 2016;47:1452-5.

16. Ates M, Kinaci E, Kose E, et al. Corona mortis: in vivo anatomical knowledge and the risk of injury in totally extraperitoneal inguinal hernia repair. Hernia. 2016;20:659-65.

17. Kacra BK, Arazi M, Cicekcibasi AE, Büyükmumcu M, Demirci S. Modified medial Stoppa approach for acetabular fractures: an anatomic study. J Trauma. 2011;71:1340-4.

18. Missankov AA, Asvat R, Maoba KI. Variations of the pubic vascular anastomoses in black South Africans. Acta Anat (Basel). 1996;155:212-4.

19. Jakubowicz M, Czarniawska-Grzesiñska M. Variability in origin and topography of the inferior epigastric and obturator arteries. Folia Morphol (Warsz). 1996;55:121-6. 


\section{Hip\& Pelvis}

Sandeep Kashyap et al. The Majority of Corona Mortis Are Small Calibre Venous Blood Vessels

20. Maneesha S, Tripta S, Richhpal S, et al. Variations of obturator artery in man. Anat Physiol. 2012;2:105.

21. Al Talalwah W. A new concept and classification of corona mortis and its clinical significance. Chin J Traumatol. 2016;19:251-4.

22. Skandalakis LJ, Androulakis J, Colborn GL, Skandalakis JE. Obturator hernia. Embryology, anatomy, and surgical applications. Surg Clin North Am. 2000;80:71-84.
23. Jensen KO, Sprengel K, Mica L, Somlyay L, Jentzsch T, Werner CML. Surgical relevance of corona mortis and clinical outcome in pelvic trauma. Austin J Anat. 2015;2: 1033.

24. Lau H, Lee F. A prospective endoscopic study of retropubic vascular anatomy in 121 patients undergoing endoscopic extraperitoneal inguinal hernioplasty. Surg Endosc. 2003;17:1376-9. 